\title{
Home FES: An Exploratory Review
}

\author{
Matthew J. Taylor (1,2,3), Sheila Schils (4), Andrew J. Ruys (1) \\ (1) Faculty of Engineering and IT, The University of Sydney, Camperdown, Australia; (2) \\ Charles Perkins Centre, The University of Sydney, Camperdown, Australia; (3) Discipline of \\ Anatomy and Histology, Faculty of Medicine and Health, The University of Sydney, \\ Camperdown, Australia; (4) EquiNew, River Falls, Wisconsin, United States of America.
}

This article is distributed under the terms of the Creative Commons Attribution Noncommercial License (CC BY-NC 4.0) which permits any noncommercial use, distribution, and reproduction in any medium, provided the original author(s) and source are credited.

\begin{abstract}
This review of literature focuses on the multiple uses of Functional Electrical Stimulation (FES) and how this modality may be a valuable home-based therapy. Papers pertaining to home FES exercise were collected using the Web of Science, Google Scholar databases and collegial hints. In our opinion, the following statements summarize the results. FES may be used to induce health benefits in populations with paralysis, and in persons with musculoskeletal, cardiorespiratory and renal pathology. The EU Project Rise showed how FES could have a variety of encouraging outcomes for patients with denervated muscles following traumatic injuries. As suggested by recent literature, FES has proven to be a viable form of exercise for elderly individuals. Thus, Home FES may be an option for patients looking for an additional form of muscle and cardiopulmonary physical therapy.
\end{abstract}

Key Words: electrical stimulation; Home FES; spinal cord injury; osteoarthritis; cardiopulmonary and renal failure; elderly; muscle weakness; physical therapy.

Eur J Transl Myol 29 (4): 283-292, 2019

In 1961, Vladimir Liberson and colleagues designed a system to electrically stimulate the common peroneal nerve of a man with hemiparesis, enabling the foot to be lifted off the ground during gait when otherwise it would have dragged across the floor. ${ }^{1}$ Indeed, if a degree of functional work is the outcome of the electrical stimulation (ES), the use of electricity to artificially activate sensory and motor nerves is known as functional electrical stimulation (FES).

In the context of spinal cord injury (SCI), it has been noted that exercise helps to reduce complications related to a sedentary lifestyle. Therefore, a FES system would allow the patient to easily adjust the type and location of their exercise on a daily basis. ${ }^{2}$

Home exercise using FES is an option which can help reduce the sequelae of diseases. Indeed, home FES, or "home-based (h-b) FES" as referred to by European teams looking at permanent denervated muscles, ${ }^{3,4}$ lends itself as an exciting way for people suffering from various conditions to exercise their skeletal muscles.

While primarily used to enable those with paralysis to train, FES research has been extended with positive metabolic outcomes to persons suffering with chronic failures of heart, ${ }^{5-7}$ lungs, ${ }^{7,8}$ and kidneys, ${ }^{7,9,10}$ and the elderly. ${ }^{11}$ There has also been a large focus on the use of
FES in populations with neurological diseases such as cerebral palsy, spinal cord injury, stroke and multiple sclerosis. $^{12}$

Therefore, it would be wise to understand the potential of FES as a therapy in the home for other populations who may seek health benefits.

The home is an environment that differs markedly from a laboratory or clinical setting. Indeed, perceptions of this difference forms the basis for work performed by researchers at the University of Sydney. We previously published reviews on how compliance to prescribed home FES has been assessed across the literature. We concluded by making some recommendations for homebased FES exercise and for the compliance measurement methods. ${ }^{13-15}$

Reading this review of actual and potential clinical applications, we hope that the notion that FES is not an esoteric method of exercise for selected populations is convincing. Indeed, extending the use of home-based FES to elderly will tremendously increase its impact on the population at large.

\section{Literature Retrieval}

Papers pertaining to home FES exercise were collected using the Web of Science, Google Scholar databases and collegial hints. In tables 1 and 2 are summarized data 
from relevant papers, with information on populations utilizing ES or home-based FES.

\section{State of the Art of Home FES}

\section{Neuromuscular Diseases}

FES has characteristically been implemented in individuals with central nervous system (CNS) diseases such as spinal cord injury and cerebral palsy. ${ }^{12}$ More generally, it has been known in the rehabilitation engineering sector for at least sixty years since Liberson's work. ${ }^{1}$ In addition, for an even longer period of time FES has been as posited by authors such as Andrews, ${ }^{16}$ who note FES use in an earlier patent by Charles Giaimo, ${ }^{17}$ in the 1950 s. The literature on FES in the home is a good reflection of the ability of FES to impart wanted benefits on individuals with neuromuscular diseases. In case studies of individuals with SCI for example, it has been demonstrated that a home FES cycling regime can increase the frequency of exercise performed by an individual, to a level much greater than that of the general population. ${ }^{18,19}$

In their case study, Dolbow \& colleagues ${ }^{18}$ argue that FES exercise is "feasible" on grounds of their participant having 93\% compliance. The individual participated in FES cycling for nine weeks in the home. The authors also suggested that home FES cycling can help quell "barriers" to exercise by SCI patients., ${ }^{2,18}$ As FES is capable of stimulating muscles that are otherwise not able to perform conactions, it is no surprise that home FES studies have elucidated positive effects of FES exercise for spinal cord injured subjects. Dolbow and colleagues (2012) reported that after a program of 3 sessions per week for 9 weeks, an individual showed an increase in lean mass, a decrease in percentage body fat and a decrease in seat pressures. ${ }^{18}$ Increases in bone mineral density (BMD) and muscle volume have also been reported in a study of four children with SCI (two FES cycling protocol and two controls). ${ }^{20}$ Subjects performed three 1-h sessions per week.

Moreover, encouraging results for a FES-cycling group have been reported for $\mathrm{VO}_{2}$ peak relative to a passive cycling group in a study of 30 children with SCI. ${ }^{20}$ FES cycling in the home is thus appears capable of bestowing a range of encouraging metabolic outcomes on individuals with paralysis.

In spite of these results, it must be noted that the literature also reports a few examples of no metabolic improvements due to FES stimulation. In Johnston et al.'s study ${ }^{21}$ for example there was no changes in VO2peak at 6 months in comparison with the baseline. The authors argue that "average percent change" was significantly different though when comparing the FES cycling with passive cycling.

In addition, some of the literature indicates no changes to lipids, ${ }^{23}$ and minimal changes to BMD. ${ }^{18,19}$ In light of such observations, it is apparent that improved metabolic results, due to FES training, for individuals with SCI show some inconsistent results, however the data is overwhelmingly promising. Individuals with stroke comprise another population which has been examined in the context of home FES exercise. Alon et al..$^{23}$ described a variety of improved outcomes to parameters such as spasticity, pain and lifting tests in their study looking at combined wrist/hand electrical stimulation and grasp training over a period of 5 wk. A similar study also showed several marked improvements of the same parameters. $^{24}$ In addition, some improvements in outcomes such as spasticity and movement have also been documented in a study of ten individuals with stroke using a Rehabilicare muscle stimulation system. ${ }^{25}$ FES thus seems able to facilitate rehabilitation after stroke.

\section{Musculoskeletal Diseases}

Electrical stimulation is a useful technique in the sense that it may be used by individuals who cannot exercise, enabling them to exercise. ${ }^{26}$ As such, it has far more uses not limited to populations with neuromuscular conditions, and has been examined by various researchers as a way of alleviating the sequelae of disease. Several groups have investigated electrical stimulation in patients suffering with osteoarthritis (OA) by various methodologies both experimental or following literature. ${ }^{27-33}$

Osteoarthritis is associated to a myriad of pathophysiological signs, including pain and, for joints with limited range of motion, unstability. ${ }^{26}$ There are various goals that should be kept in mind when aiming to reduce the burden of disease with FES or by other means. Increasing muscle strength is the fundamental aim of $\mathrm{OA}$ treatments, to increase leg strength and prevent muscle wasting. ${ }^{34}$ A characteristic aim of treatment in knee disorders, is to increase quadriceps strength. ${ }^{35}$ Typically pain in the knee prevents use of the muscle, leading to its' weakness, as seen in work by Slemenda \& colleagues. ${ }^{36,37}$ Functionally this can lead to a range of biomechanical impairments, specifically preventing stair-walking. ${ }^{38}$ Weak quadriceps muscles following OA and/or total knee arthroplasty (TKA) has been well-reported in the literature. ${ }^{39,40}$ Through application of electricity to the quadriceps, various groups have reported attenuation in these marked deficits. When electrical stimulation was used in OA groups results included; quadriceps crosssectional area, ${ }^{39}$ comparable pain relief to an "educationonly" regime, ${ }^{28}$ and increased quadriceps strength when used with dedicated physiotherapy. ${ }^{29}$ Indelibly the physiological benefits of FES may be harnessed in various times of the OA treatment spectrum. Avramidis et al. suggested that use of stimulation following a total knee arthroplasty may speed up the rehabilitation process. ${ }^{3,41}$ However, another potential application of FES is pre-surgery, as Walls \& colleagues proposed. ${ }^{32}$ The authors investigated use of ES in a "prehabilitation" context, prior to total knee arthroplasty surgery. They noted that stimulation can increase isometric muscle strength, but this only commenced after a period of six weeks. $^{32}$ 
Whether or not one performs electrical stimulation before or after surgery of course may require further investigation. ${ }^{3}$ However, collectively these results suggest that FES is a useful therapy for muscle rehabilitation in the OA cohort. In addition, FES may be an ideal choice of therapy in this context, as it has been suggested that OA therapies are usually administered in the home. ${ }^{3,41}$ In addition, home-based FES has been shown to reduce muscle spasms in equines and this conclusion can be easily transferred to the human population. ${ }^{42}$ Symmetry of movement is important for pain and injury reduction and the use of FES has been also shown to improve multifidi symmetry when used bilaterally over the spine. ${ }^{43}$ Finally, and perhaps most importantly, FES has been shown to improve mitochondria density and distribution which is an exciting benefit when evaluating the use of FES for muscle conditioning. ${ }^{44}$

\section{FES Goal Setting Activities}

The FES exercise may be carried out in a variety of modalities such as, cycling, ${ }^{45}$ rowing, ${ }^{46}$ or walking. ${ }^{47}$ Recently there was great interest in motivating SCI patients to perform FES cycling by organising competitions among FES Cycling SCI athletes, such as the First Cybathlon Competition in 2016. This was achieved after a long training performed at home after careful instructions in clinics or outpatient services. ${ }^{48}$

\section{Permanent Denervated Muscle and the EU Project Rise}

Since the late 1980's, it was put forward that FES may be used for SCI patients whom have intact lower motor neurons. ${ }^{12}$ On the other hand, the European Project RISE is an example of how patients with permanent denervated muscles may benefit from home-based FES protocol up to perform standing and in-place-stepping trainings. ${ }^{3}$ Initially, there were several challenges to the implementation of FES for denervated muscles. Mayr and colleagues (2002) at the Medical University of Vienna discuss how FES devices at the time were unable to provide the appropriate stimulation required for permanently denervated muscle activation. ${ }^{49}$ In particular, permanent denervation of skeletal muscles poses many challenges that are not seen in stimulation of normal "innervated" muscles.

The problems even worsen, when an increased amount of adipocytes and collagen replaces atrophing muscle tissue after years of persistent denervation. ${ }^{3}$ Another important fact in stimulating permanently denervated muscle is that the FES stimulation parameters differ substantially from those for innervated muscles (e.g., those of thoracic level SCI). Denervated muscle that has not been activated for years requires a waveform hundreds of milliseconds longer than normal innervated muscle. Kern and colleagues implemented pulse widths in the range of 120$150 \mathrm{~ms}$ in their study of 25 patients with "complete conus/cauda equina lesion", 3,4
Indeed, they found that after only three months of denervation, the functional and histopathological state of muscles differs substantially from normal innervated muscle. A likely explanation for the need of this unusually large pulse width is that there is poor excitability, and thus contractility, of muscle fibres when they are denervated for several months. Another important consideration is the lower or much lower excitability (dependent on the length of time from SCI) of denervated muscle as opposed to motor and sensory nerves. ${ }^{3}$ Long-term denervated muscle fibers (typically after six-twelve month after motor denervation) have a low excitability (10-150 ms pulse width is required to initiate contraction), compared with nerves that have a much higher excitability $(0.1-1 \mathrm{~ms}$ pulse width) at an equivalent stimulus amplitude. ${ }^{3}$ The literature on the EU Project Rise offers insights into the use of FES for denervated muscle training in the home. Five main original results (some of them, unexpected) were obtained while training a group of complete SCI patients with permanent lower motor neuron denervation of leg muscles (i.e, complete and permanent Conus and Cauda Equina Syndrome).

These promising findings are:

1. Time course of muscle atrophy: Progression of muscle atrophy in complete denervated human muscles takes several years (five to ten years) to reach the final tage of muscle fibro-fatty degeneration. This is in contrast with the process in rodents, that was described to be from six to nine months..$^{3,4}$

2. Stimulation parameters required for long-term denervated muscles: The permanently denervated muscle responds to electrical stimulation, but requires long bidirectional stimuli (5-10 ms if FES starts from three to six months of denervation, and to up to $150-300 \mathrm{~ms}$ if FES starts between two to six years post-SCI). ${ }^{3,4}$

3. Contractility changes during two years of home FES: Atrophying muscles were rescued by 2 years of homebased functional electrical stimulation (hbFES) when a purpose developed electrical stimulator, ${ }^{50}$ now commercially available at the Company Schuhfried, Wien (Austria), ${ }^{51}$ provided the needed high currents to large anatomically-shaped surface electrodes that need to completely cover the permanent denervated quadriceps muscles. ${ }^{3,4}$ The progressive rehabilitation strategy may start with single twitch contractions during the first three to six months of hbFES. Then moves to sustained tetanic contractions when excitation/contraction improved, so that FES may be provided in train of impulses at $20 \mathrm{~Hz}$. These changes in parameters are due to the recovered excitability/contractility of the long-term trained denervated muscle, usually occurring after three to six months of hbFES. ${ }^{3,4}$

4. Functional outcomes of home stimulation: Many trained SCI patients reached a stage of muscle recovery by hbFES that improved the contractile properties of the quadriceps muscles to a level that allowed them to stand 


\begin{tabular}{|c|c|}
\hline \multicolumn{2}{|c|}{ Table 1. State of the Art: Home Electrical Stimulation Studies } \\
\hline Condition & References \\
\hline Stroke & $\begin{array}{ll}\text { - } & \text { Alon et al., } 2003^{23} \\
\text { - } & \text { Alon \& Ring, } 2003^{24} \\
\text { - } & \text { Chan et al. } 2015^{66} \text { (TENS) } \\
\text { - } & \text { Sullivan \& Hedman, } 2007^{25} \text { (arm hemiparesis) }\end{array}$ \\
\hline Foot drop & - $\quad$ Prenton et al., $2014^{67}$ \\
\hline Posterior tibial tendon dysfunction & $\begin{array}{l}\text { Bek et al., } 2012^{68} \text { [counter-example as argue for in-centre } \\
\text { FES] }\end{array}$ \\
\hline $\begin{array}{l}\text { Spinal cord injury, paraplegia, } \\
\text { tetraplegia }\end{array}$ & $\begin{array}{ll}\text { - } & \text { Berry et al., } 2008^{69} \\
\text { - } & \text { Berry et al., } 2012^{70} \\
\text { - } & \text { Bremner et al., } 1992^{19} \\
\text { - } & \text { Dolbow et al., } 2012^{2} \\
\text { - } & \text { Dolbow et al., } 2012^{18} \\
\text { - } & \text { Dolbow et al., } 2012^{19} \text { (veterans) } \\
\text { - } & \text { Donaldson et al., } 2000^{71} \\
\text { - } & \text { Johnston et al., } 2008^{20} \\
\text { - } & \text { Johnston et al., } 2009^{21} \text { (children); } \\
\text { - } & \text { Mödlin et al., } 2005^{72} \text { (with quadriceps denervation); } \\
\text { - } & \text { Moynahan et al., } 1996^{73} \text { (adolescents); } \\
\text { - } & \text { Sipski et al., } 1993^{74}\end{array}$ \\
\hline $\begin{array}{l}\text { Permanent muscle denervation and } \\
\text { complete conus cauda syndrome }\end{array}$ & $\begin{array}{ll}\text { - } & \text { Kern, } \mathbf{1 9 9 5}^{75} \\
\text { - } & \text { Kern et al., 200976 } \\
\text { - } & \text { Kern et al., 2010 } \\
\text { - } & \text { Kern et al. 2010 } \\
\text { - } & \text { Kern, 2014 } \\
\text { - } & \text { Kern \& Carraro, } 2014^{3} \\
\text { - } & \text { Zanato et al., 2010 } \\
\text { - } & \text { Zanato et al., 2011 } \\
\text { - } & \text { Zanato et al., 2013 } \\
\end{array}$ \\
\hline Multiple sclerosis & - $\quad$ Coote et al., $2015^{77}$ \\
\hline Knee osteoarthritis & 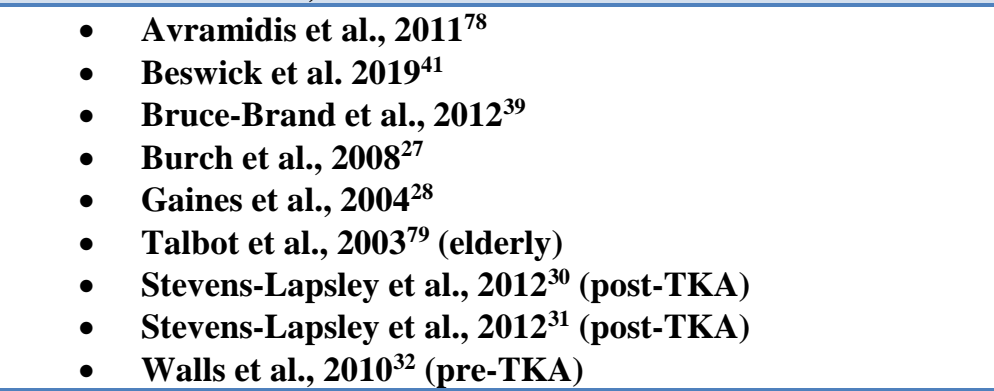 \\
\hline
\end{tabular}

and perform steps-in-place training. Further, some SCI persons could walk up to $100-200 \mathrm{~m}^{3,4}$

5. CT and biopsy results: The improvement in functional outcomes were correlated to the increased muscle mass of both quadriceps and hamstrings muscles documented by Muscle Color Computed Tomography Imaging. ${ }^{3,4}$ In addition, after 2 years of FES training, the results of microscopic and ultramicroscopic analyses of the quadriceps muscles biopsied before and after two years of home-based FES training showed an improvement in muscle fiber size and ultrastructure, that fully explain the recovered contractility of the permanent denervated muscles. $^{3,4}$ Interestingly, it was also recently demonstrated that the skin exposed to two years of hbFES (to induce contractions of the denervated quadriceps muscles) showed an improvement in epidermis thickness. ${ }^{52}$ In a similar fashion, the Italian branch of the RISE project (Rise2-Italy) also offers similar prospects. For example, in their case studies of leg denervated muscles, Zanato et al. $^{53}$ found that hyperaemia of muscle may be sustained upon cessation of electrical stimulation. Moreover, FES stimulation for six months has resulted in an increase in tibialis anterior thickness documented by ultrasound analyses. ${ }^{54,55}$ 


\begin{tabular}{|c|c|}
\hline Condition & References \\
\hline Elderly Muscle Training & $\begin{array}{l}\text { - } \quad \text { Barberi et al., } 2015^{3} \\
\text { - } \quad \text { Carraro et al., } 2017^{63} \\
\text { - } \quad \text { Caulfield et al., } 2018^{3} \\
\text { - } \quad \text { Cvecka et al., } 2015^{31} \text { (healthy) } \\
\text { - } \quad \text { Hendling et al., } 2013^{80} \\
\text { - } \quad \text { Kern et al., 2014 } \\
\text { - } \quad \text { Mangione et al., } 2010^{81} \text { (post-hip fracture) } \\
\text { - } \quad \text { Protasi, } 2015^{3} \\
\text { - } \quad \text { Sarabon et al., } 2015^{3} \\
\text { - } \quad \text { Tezze et al., } 2018^{64} \\
\text { - } \quad \text { Zampieri et al., } 2015^{81} \\
\text { - } \text { Zampieri et al., } 2015^{82} \\
\text { et al., } 2016^{62}\end{array}$ \\
\hline Chronic heart failure & $\begin{array}{ll}\text { - } & \text { Harris et al., } 2003^{5} \\
\text { - } & \text { Jones et al, } 2016^{7} \\
\text { - } & \text { Soska et al., 2014 }\end{array}$ \\
\hline Chronic obstructive pulmonary disease & $\begin{array}{ll}- & \text { Neder et al., 2002 } \\
\text { - } & \text { Jones et al., 2016 }\end{array}$ \\
\hline Chronic kidney failure & $\begin{array}{ll}\text { - } & \text { Brüggemann et al., } 2017^{9} \\
\text { - } & \text { Jones et al., } 2016^{7} \\
\text { - } & \text { McGregor et al., } 2018^{10} \\
\end{array}$ \\
\hline Cancer & $\begin{array}{ll}\text { - } & \text { Coletti et al., 2016 } \\
\text { - } & \text { Hiroux et al., 20166 } \\
\text { - } & \text { Windholz et al., 2014 }\end{array}$ \\
\hline Bilateral patellofemoral pain syndrome & $\begin{array}{ll}\text { - } & \text { Bily et al., } 2008^{84} \\
\text { - } & \text { Sajer, } 2017^{3} \\
\end{array}$ \\
\hline Sciatic nerve injury & $\begin{array}{l}\text { - Zanato et al., } 2010^{53} \\
\text { - } \quad \text { Zanato et al., 2011 } 2011^{54} \\
\text { - } \quad \text { Zanato et al., 2013 }\end{array}$ \\
\hline Peripheral nerve lesion & - Rossato et al., $2009^{85}$ \\
\hline Spastic diplegic cerebral palsy & - Johnston \& Wainwright, $2011^{86}$ \\
\hline Equine muscle training & $\begin{array}{ll}\text { - } & \text { Schils \& Turner, } 2014^{44} \\
\text { - } & \text { Schils et al, } 2015^{42} \\
\text { - } & \text { Isbell et al, } 2017^{43} \\
\end{array}$ \\
\hline
\end{tabular}

\section{Other Diseases}

The literature in Tables 1 and 2 also indicates that electrical stimulation has been used for cardiopulmonary conditions such as chronic obstructive pulmonary disease $(\mathrm{COPD})^{8}$ and chronic heart failure (CHF). ${ }^{5,6}$ Neder et al. ${ }^{8}$ for example, proposed that electrical stimulation can lead to user-specified alleviation of dyspnoea, as assessed by a questionnaire. In their study of NMES for heart failure, Harris et al. ${ }^{5}$ showed that exercise parameters can increase with NMES comparable to standard cycling. A similar result was obtained in another study that demonstrated addition of EMS, or EMS by itself, had no added benefit to changing oxygen uptake or power generation in comparison with standard "aerobic training". 6

These studies offer initial insight into potential use of FES exercise in these populations, but to confirm those results further investigations are needed. On the other hand, recent literature provides strong evidence of the efficacy of FES (and hbFES) in the cases of "Intradialytic Neuromuscular Electrical Stimulation on Strength and Muscle Architecture in Patients suffering with Chronic Kidney Failure, ${ }^{9,10,56}$ and many other chronic diseases. ${ }^{7}$ Anyhow, these studies illustrate some important concepts regarding the practical use and purpose of home-based 
FES. Firstly, concomitant electrical stimulation and standard best practice may not yield added therapeutic benefits. ${ }^{6}$ However, the fact that ES may be comparable with such best practice, ${ }^{5}$ may suggest it is a way in which chronic heart failure patients can perform "useful" exercise. Harris et al. ${ }^{5}$ highlighted that FES is particularly useful for use in populations where normal exercise may be difficult to perform, as it may be done so while individuals are "sedentary" or even bed-ridden. Further investigations into the added utility of FES over other forms of exercise in these populations is at least justified.

\section{Aging}

We list here some of the literature data that provide promising results on the effects of home FES in "normal" (that is, over 65 years persons without any, or at least stable, pharmacological therapy) aging persons. ${ }^{57}$

Heartened by the strong evidence of the efficacy of hbFES for recovery of denervated muscles in complete SCI persons (see above) ${ }^{3,4}$ and of the value of a life-long amateur sport activity in delaying aging decay, ${ }^{58,59}$ Helmut Kern and his group of Austrian and Italian collaborators, designed and implemented a series of trials demonstrating that: i) long-term high level exercise delays age-associated skeletal muscle decline $e^{3,60-63}$ and ii) that home FES at least mimics volitional exercise in elderly persons. ${ }^{64,65}$

\section{Conclusions}

This review provide a general directive for those who are considering FES as an alternative form of training/rehabilitation for their patients. The European Project RISE has been a successful example of home based FES, that can be adapted for other populations in the home leading to physiological changes beneficial for patients. Together with the literature presented, this review showed that FES is not confined to treating those with neurological diseases, but offers potential in populations suffering with musculoskeletal, cardiopulmonary and kidney pathologies and in sedentary or bed-ridden elderly. There is still much more work required to implement electrical stimulation in home, but premises are heartening. In summary, this review shows that: i) home FES may be used to induce health benefits in populations with paralysis, and in persons with musculoskeletal, cardiorespiratory and renal pathology; ii) The EU Project Rise showed how FES can have a variety of encouraging outcomes for patients with permanent denervated muscles following traumatic injuries; iii) Recent literature suggests that FES is a viable form of exercise for elderly individuals. Thus, home FES may be a sensible option for patients looking for an additional form of cardiopulmonary and muscle training/rehabilitation.

\section{List of acronyms}

BMD - bone mineral density

$\mathrm{CHF}$ - chronic heart failure
CNS - central nervous system

COPD - chronic obstructive pulmonary disease

EMS - electrical muscle stimulation/

electromyostimulation

ES - electrical stimulation

FES - functional electrical stimulation

hbFES - home-based FES

NMES - neuromuscular electrical stimulation

$\mathrm{OA}$ - osteoarthritis

SCI - spinal cord injury

TKA - total knee arthroplasty

$\mathrm{VO}_{2}$ (peak) - oxygen uptake (peak)

\section{Authors contributions}

MJT drafted the manuscript and was responsible for literature review and critical synthesis and analysis of literature, SS was responsible for review of the equine literature and assisted with reformatting and organisation of the work, AJR was the primary supervisor of related thesis work.

MJT is a former PhD student at the University of Sydney, Australia. He is currently a Researcher: Learning, Technology and Innovation at the University of Sydney Business School.

\section{Acknowledgments}

The authors would like to thank Professor Ugo Carraro, MD, who gave insightful critiques of the work and recommendations regarding pertinent references. In addition, we would like to thank Professor Helmut Kern, $\mathrm{MD}, \mathrm{PhD}$, for his clinical comments regarding the work.

\section{Funding}

No funding was obtained for this project.

\section{Conflict of Interest}

The authors have no conflicts to disclose.

\section{Ethical Publication Statement}

We confirm that we have read the Journal's position on issues involved in ethical publication and affirm that this report is consistent with those guidelines.

\section{Corresponding Author}

Dr. Matthew James Taylor, Level 5, Abercrombie Building, The University of Sydney, NSW, 2006, Australia. Mobile Phone: + 61478033859 .

Email:mj.taylor.1290@gmail.com

E-mails of co-authors

Sheila Schils: sbschils@EquiNew.com

Andrew J. Ruys: andrew.ruys@sydney.edu.au

\section{References}

1. Liberson WT, Holmquest, HJ, Scot, D, Dow, M. Functional electrotherapy: Stimulation of the peroneal nerve synchronized with the swing phase of the gait of hemiplegic patients. Arch Phys Med Rehabil 1961;42:101-5. 
2. Dolbow DR, Gorgey AS, Ketchum JM, et al. Exercise adherence during home-based Functional Electrical Stimulation cycling by individuals with spinal cord injury. Am J Phys Med Rehabil 2012;91:922-30.

3. Kern H, Hofer C, Loefler S, et al. Atrophy, ultrastructural disorders, severe atrophy and degeneration of denervated human muscle in SCI and Aging. Implications for their recovery by Functional Electrical Stimulation, updated 2017. Neurol Res 2017;39:660-6. http://dx.doi.org/10.1080/01616412.2017.1314906

4. Kern H, Carraro U, Adami N, et al. Home-based functional electrical stimulation rescues permanently denervated muscles in paraplegic patients with complete lower motor neuron lesion. Neurorehabil Neural Repair 2010;24:709-21.

5. Harris S, LeMaitre JP, Mackenzie G, et al. A randomised study of home-based electrical stimulation of the legs and conventional bicycle exercise training for patients with chronic heart failure. Eur Heart J 2003;24:871-8.

6. Soska V, Dobsak P, Pohanka M, et al. Exercise training combined with electromyostimulation in the rehabilitation of patients with chronic heart failure: A randomized trial. Biomed Pap Med Fac Univ Palacky Olomouc Czech Repub 2014;158:98106.

7. Jones S, Man WD, Gao W, et al. Neuromuscular electrical stimulation for muscle weakness in adults with advanced disease. Cochrane Database Syst Rev 2016;10:CD009419.

8. Neder JA, Sword D, Ward SA, et al. Home based neuromuscular electrical stimulation as a new rehabilitative strategy for severely disabled patients with chronic obstructive pulmonary disease (COPD). Thorax 2002;57:333-7.

9. Brüggemann AK, Mello CL, Dal Pont $\mathrm{T}$, et al. Effects of Neuromuscular Electrical Stimulation During Hemodialysis on Peripheral Muscle Strength and Exercise Capacity: A Randomized Clinical Trial. Arch Phys Med Rehabil 2017;98:822-31.e1. doi: 10.1016/j.apmr.2016.12.009.

10. McGregor G, Ennis S, Powell R, et al. Feasibility and effects of intra-dialytic low-frequency electrical muscle stimulation and cycle training: A pilot randomized controlled trial. PLoS One 2018;13:e0200354. doi: 10.1371/journal.pone.0200354. eCollection 2018.

11. Caulfield B, Prendergast A, Rainsford G, Minogue C. Self directed home based electrical muscle stimulation training improves exercise tolerance and strength in healthy elderly. 35th Annual International Conference of the IEEE EMBS, Osaka, Japan, 3-7 July 2013.

12. Kralj A, Bajd T. Functional Electrical Stimulation: Standing and Walking after Spinal Cord Injury.
CRC Press, Inc., Boca Raton, Florida, United States of America, 1989.

13. Taylor MJ, Fornusek C, Ruys AJ. The duty cycle in Functional Electrical Stimulation research. Part II: Duty cycle multiplicity and domain reporting. Eur J Transl Myol 2018;28:7733. doi: 10.4081/ejtm.2018.7733.

14. Taylor MJ, Ruys AJ, Fornusek C, et al. Lessons from Vienna: stakeholder perceptions of functional electrical stimulation technology and a conceptual model for practice. Disabil Rehabil Assist Technol 2018:1-8. doi: 10.1080/17483107.2018.1513573.

15. Taylor MJ, Ruys AJ, Kern H, et al. Functional Electrical Stimulation (FES) in the home: Compliance measurements. Biology, Engineering and Medicine 2019;4:1-3.

16. Andrews BJ. History of Motor FES: who were the pioneers? Proceedings of the 16thAnnual International FES Society Conference, São Paulo, Brazil, South America, 8-11 September 2011.

17. Giaimo, CV. Electrical control of partially denervated muscles. US Patent 2737183. 1956. Accessed via Google Patents: https://patents.google.com/patent/US2737183, $7 / 3 / 18$.

18. Dolbow DR, Gorgey AS, Cifu DX, et al. Feasibility of home-based functional electrical stimulation cycling: case report. Spinal Cord 2012;50:170-1.

19. Dolbow DR, Gorgey AS, Moore JR, Gater DR. Report of practicability of a 6-month home-based functional electrical stimulation cycling program in an individual with tetraplegia. J Spinal Cord Med 2012;35:182-6.

20. Johnston TE, Smith BT, Oladeji O, et al. Outcomes of a home cycling program using Functional Electrical Stimulation or passive motion for children with spinal cord injury: A case series. J Spinal Cord Med 2008;31:215-21.

21. Johnston TE, Smith BT, Mulcahey MJ, et al. A randomized controlled trial on the effects of cycling with and without electrical stimulation on cardiorespiratory and vascular health in children with spinal cord injury. Arch Phys Med Rehabil 2009;90:1379-88.

22. Bremner LA, Sloan KE, Day RE, et al. A clinical exercise system for paraplegics using functional electrical stimulation. Paraplegia 1992;30:647-55.

23. Alon G, Sunnerhagen KS, Geurts ACH, Ohry A. A home-based, self-administered stimulation program to improve selected hand functions of chronic stroke. NeuroRehabilitation 2003;18:215-25.

24. Alon G, Ring $H$. Gait and hand function enhancement following training with a multisegment hybrid-orthosis stimulation system in stroke patients. J Stroke Cerebrovasc Dis 2003;12:209-16.

25. Sullivan JE, Hedman LD. Effects of home-based sensory and motor amplitude electrical stimulation 
on arm dysfunction in chronic stroke. Clin Rehabil 2007;21:142-50.

26. Giggins OM, Fullen BM, Coughlan GF. Neuromuscular electrical stimulation in the treatment of knee osteoarthritis: a systematic review and meta-analysis. Clin Rehabil 2012;26:867-81.

27. Burch FX, Tarro JN, Greenberg JJ, Carroll WJ. Evaluating the benefits of patterned stimulation in the treatment of osteoarthritis of the knee. A multicenter, randomized, single-blind, controlled study with an independent masked evaluator. Osteoarthritis Cartilage 2008;16:865-72.

28. Gaines JM, Metter J, Talbot LA. The effect of neuromuscular electrical stimulation on arthritis knee pain in older adults with osteoarthritis of the knee. Appl Nurs Res 2004;17:201-6.

29. Kachanathu SJ, Anand B, Nuhmani S, Hafez AR. Efficacy of neuromuscular electrical stimulation on quadriceps femoris muscle in patients with knee osteoarthritis. Phys Med Rehab Kuror 2014;24:8791.

30. Stevens-Lapsley JE, Balter JE, Wolfe P, et al. Relationship between intensity of quadriceps muscle neuromuscular electrical stimulation and strength recovery after total knee arthroplasty. Phys Ther 2012;92:1187-96.

31. Stevens-Lapsley JE, Balter JE, Wolfe P, et al. Early neuromuscular electrical stimulation to improve quadriceps muscle strength after total knee arthroplasty: A randomized controlled trial. Phys Ther 2012;92:210-26.

32. Walls RJ, McHugh G, O'Gorman DJ, et al. Effects of preoperative neuromuscular electrical stimulation on quadriceps strength and functional recovery in total knee arthroplasty. A pilot study. BMC Musculoskelet Disord 2010;11:119.

33. Zeng $\mathrm{C}, \mathrm{Li} \mathrm{H}$, Yang $\mathrm{T}$, et al. Electrical stimulation for pain relief in knee osteoarthritis: systematic review and network meta-analysis. Osteoarthritis Cartilage 2015;23:189-202.

34. Vaz MA, Baroni BM, Geremia JM, et al. Neuromuscular electrical stimulation (NMES) reduces structural and functional losses of quadriceps muscle and improves health status in patients with knee osteoarthritis. J Orthop Res 2013;31:511-6.

35. Sharma L, Dunlop D, Cahue S, et al. Quadriceps strength and osteoarthritis progression in malaligned and lax knees. Ann Intern Med 2003;138:613-9.

36. Slemenda C, Brandt KD, Heilman DK, et al. Quadriceps weakness and osteoarthritis of the knee. Ann Intern Med 1997;127:97-104.

37. Slemenda C, Heilman DK, Brandt KD, et al. Reduced quadriceps strength relative to body weight. A risk factor for knee osteoarthritis in women? Arthritis Rheum 1998;11:1951-9.
38. Gür H, Çakin N. Muscle mass, isokinetic torque, and functional capacity in women with osteoarthritis of the knee. Arch Phys Med Rehabil 2003;84:1534-41.

39. Bruce-Brand RA, Walls RJ, Ong JC, et al. Effects of home-based resistance training and neuromuscular electrical stimulation in knee osteoarthritis: a randomized controlled trial. BMC Musculoskelet Disord 2012;13:118.

40. Thomas AC, Stevens-Lapsley JE. Importance of attenuating quadriceps activation deficits after total knee arthoplasty. Exerc Sport Sci Rev 2012;40:95101.

41. Beswick AD, Dennis J, Gooberman-Hill, et al. Are perioperative interventions effective in preventing chronic pain after primary total knee replacement? A systematic review. BMJ Open 2019;9:e028093. doi: 10.1136/bmjopen-2018-028093.

42. Schils S, Carraro U, Turner T, et al. Functional Electrical Stimulation (FES) for equine muscle hypertonicity: histological changes in mitochondrial density and distribution. J Equine Vet Sci 2015;35:907-16.

43. Isbell D, Schils S, Oakley S. Functional Electrical Stimulation (FES) and the effect on Equine Multifidi Asymmetry. American Association of Equine Practitioners (AAEP) Proceedings, November, 2017, San Antonio, Texas, USA.

44. Schils SJ, Turner, TA. Functional electrical stimulation for equine epaxial muscle spasms: retrospective study of 241 clinical cases. Comp Ex Phys 2014;10:89-97.

45. Fornusek C. An isokinetic functional electrical stimulation leg cycle ergometer for individuals with spinal cord injury. Doctor of Philosophy $(\mathrm{PhD})$ thesis, The University of Sydney, 2005.

46. Ektas N, Yusoff NM, Smith R, et al. Development of a sliding stretcher FES-rowing system. 19th International Functional Electrical Stimulation Society (IFESS) Conference, Kuala Lumpur, Malaysia, 2014.

47. Solomonow M, Baratta R, Hirokawa S, et al. The RGO Generation II: Muscle stimulation powered orthosis as a practical walking system for thoracic paraplegics. Orthopedics 1989;12:1309-15.

48. Coste CA, Bergeron V, Berkelmans R, et al. Comparison of strategies and performance of functional electrical stimulation cycling in spinal cord injury pilots for competition in the first ever CYBATHLON. Eur J Transl Myol 2017;27:7219. Published online 2017 Dec 5. doi: 10.4081/ejtm.2017.7219.

49. Mayr W, Hofer C, Bijak M, et al. Functional Electrical Stimulation (FES) of denervated muscles: Existing and prospective technological solutions. Basic Appl Myol. 2002;12:287-90.

50. Bijak M, Rakos M, Hofer C, et al. Stimulation parameter optimization for FES supported standing 
up and walking in SCI patients. Artif Organs 2005;29:220-3.

51. Available at http://schuhfriedmed.at/ stimuletteen/stimulette-den $2 x$ -

52. Albertin $\mathrm{G}$, Hofer $\mathrm{C}$, Zampieri $\mathrm{S}$, et al. In complete SCI patients, long-term functional electrical stimulation of permanent denervated muscles increases epidermis thickness. Neurol Res 2018;40:277-282.

doi: 10.1080/01616412.2018.1436877.

53. Zanato, R, Martino, L, Carraro, U, et al. Ecomiografia funzionale: analisi di spessori, ecostruttura, contrazione e perfusione del muscolo normale e denervato. Eur J Transl Myol - Basic Applied Myology 2010;1:33-40. [Abstract in English, full text in Italian].

54. Zanato, R, Martino, L, Stramare, R. Ecomiografia funzionale del muscolo umano denervato: primi risultati. Eur J Transl Myol - Basic Applied Myology 2011;21:3-29. [Abstract in English, full text in Italian].

55. Zanato R, Stramare R, Boato N, et al. Dynamic echomyography shows that FES in peripheral denervation does not hamper muscle reinnervation. Biomed Tech 2013;58:(Suppl. 1) pii: /j/bmte.2013.58.issue-s1-A/bmt-2013-4034/bmt2013-4034.xml. doi: 10.1515/bmt-2013-4034. Epub 2013 Sep 7.

56. Schardong J, Dipp T, Bozzeto CB, et al. Effects of Intradialytic Neuromuscular Electrical Stimulation on Strength and Muscle Architecture in Patients With Chronic Kidney Failure: Randomized Clinical Trial.Artif Organs 2017;41:1049-58. doi: 10.1111/aor.12886. Epub 2017 Jun 16.

57. Mitchell WK, Williams J, Atherton $\mathrm{P}$, et al. Sarcopenia, dynapenia, and the impact of advancing age on human skeletal muscle size and strength; a quantitative review. Front Physiol 2012;3:260. doi: 10.3389/fphys.2012. 00260. eCollection 2012.

58. Gava P, Kern H, Carraro U. Age-associated power decline from running, jumping, and throwing male masters world records. Exp Aging Res 2015;41:115-35.

59. Mosole S, Carraro U, Kern H, et al. Long-term high level exercise promotes muscle reinnervation with age. J Neuropathol Exp Neurol 2014;73(4):284-94. doi: 10.1097/NEN.0000000000000032.

60. Kern H, Barberi L, Löfler S, et al. Electrical stimulation counteracts muscle decline in seniors. Front Aging Neurosci 2014 Jul 24;6:189. doi: 10.3389/fnagi.2014.00189. eCollection 2014

61. Zampieri S, Pietrangelo L, Loefler S, et al. Lifelong physical exercise delays age-associated skeletal muscle decline. J Gerontol A Biol Sci Med Sci 2015;70: 163-73.

62. Zampieri S, Mammucari C, Romanello V, et al. Physical exercise in aging human skeletal muscle increases mitochondrial calcium uniporter expression levels and affects mitochondria dynamics. Physiol Rep 2016;4(24). pii: e13005. doi: 10.14814/phy2.13005. Erratum in: Physiol Rep 2017 Mar;5(6).

63. Carraro U, Kern H, Gava P, et al. Recovery from muscle weakness by exercise and FES: lessons from Masters, active or sedentary seniors and SCI patients. Aging Clin Exp Res 2017;29:579-590. doi: 10.1007/s40520-016-0619-1. Epub 2016 Sep 3. Review.

64. Tezze C, Romanello V, Desbats MA, et al. AgeAssociated Loss of OPA1 in Muscle Impacts Muscle Mass, Metabolic Homeostasis, Systemic Inflammation, and Epithelial Senescence. Cell Metab. 2017;25:1374-89.e6. doi: 10.1016/j.cmet.2017.04.021. Epub 2017 May 25.

65. Mayr W, Bijak M, Rafolt D, et al. Basic design and construction of the Vienna FES implants: existing solutions and prospects for new generations of implants. Med Eng Phys 2001;23:53-60.

66. Chan BKS, Ng SSM, Ng GYF. A home-based program of transcutaneous electrical nerve stimulation and task-related trunk training improves trunk control in patients with stroke: a randomized controlled clinical trial. Neurorehabil Neural Repair 2015;29:70-79.

67. Prenton S, Kenney LP, Stapleton C, et al. Feasibility study of a take-home array-based Functional Electrical Stimulation system with automated setup for current functional electrical stimulation users with foot-drop. Arch Phys Med Rehabil 2014;95:1870-7.

68. Bek N, Simsek IE, Erel S, et al. Home-based general versus center-based selective rehabilitation in patients with posterior tibial tendon dysfunction. Acta Orthop Traumatol Turc 2012;46:286-292.

69. Berry HR, Perrett C, Saunders BA, et al. Cardiorespiratory and Power Adaptations to Stimulated Cycle Training in Paraplegia. Med Sci Sport Exerc. 2008;40:1573-80.

70. Berry HR, Kakebeeke TH, Donaldson N, et al. Energetics of paraplegic cycling: Adaptations to 12 months of high volume training. Technol Health Care 2012;20:73-84.

71. Donaldson N, Perkins TA, Fitzwater R, et al. FES cycling may promote recovery of leg function after incomplete spinal cord injury. Spinal Cord 2000;38:680-2.

72. Mödlin M, Forstner C, Hofer C, et al. Electrical stimulation of denervated muscles: first results of a clinical study. Artif Organs 2005;29:203-6.

73. Moynahan M, Mullin C, Cohn J, et al. Home use of a Functional Electrical Stimulation system for standing and mobility in adolescents with spinal cord injury. Arch Phys Med Rehabil 1996;77:100513.

74. Sipski ML, Alexander CJ, Harris M. Long-term use of computerized bicycle ergometry for spinal cord 


\section{Review on Home FES}

Eur J Transl Myol 29 (4): 283-292, 2019

injured subjects. Arch Phys Med Rehabi. 1993;74:238-41.

75. Kern H. Funktionelle Elektrostimulation paraplegischer patienten. Österr Z Phys Med 1995;5:1-79.

76. Kern H, Hofer C, Mayr W, Carraro U. European Project RISE: Partners, protocols, demography. Basic Appl Myol 2009;19:211-6.

77. Coote S, Hughes L, Rainsford G, et al. Pilot randomized trial of progressive resistance exercise augmented by Neuromuscular Electrical Stimulation for people with multiple sclerosis who use walking aids. Arch Phys Med Rehab 2015;96:197-204.

78. Avramidis K, Karachalios T, Popotonasios K, et al. Does Electric Stimulation of the Vastus Medialis Muscle Influence Rehabilitation After Total Knee Replacement? Orthopedics 2011;34:175. doi.org/10.3928/01477447-20110124-06

79. Talbot LA, Gaines JM, Ling SM, Metter J. A home-based protocol of electrical muscle stimulation for quadriceps muscle strength in older adults with osteoarthritis of the knee. J Rheumatol 2003;30:1571-8.

80. Hendling M, Krenn M, Haller MA, et al. Compliance monitoring of home based electrical stimulation training of elderly subjects. Biomed Tech 2013;58: (Suppl. 1). ii: /j/bmte.2013.58.issues1-A/bmt-2013-4006/bmt-2013-4006.xml. doi: 10.1515/bmt-2013-4006. Epub 2013 Sep 7.

81. Mangione KK, Craik RL, Palombaro KM, et al. Home-based leg-strengthening exercise improves function 1 year after hip fracture: A randomized controlled study. J Am Geriatr Soc 2010;58:19117.

82. Zampieri S, Mosole S, Löfler S, et al. Physical Exercise in Aging: Nine Weeks of Leg Press or Electrical Stimulation Training in 70 Years Old Sedentary Elderly People. Eur J Transl Myol 2015;25:237-42. doi: 10.4081/ejtm.2015.5374. eCollection 2015 Aug 24. Review.

83. Windholz, T, Swanson, T, Vanderbyl, BL, Jagoe, RT. The feasibility and acceptability of neuromuscular electrical stimulation to improve exercise performance in patients with advanced cancer: a pilot study. BMC Palliat Care 2014;13:23.

84. Bily W, Trimmel L, Mödlin M, et al. Training program and additional electric muscle stimulation for patellofemoral pain syndrome: A pilot study. Arch Phys Med Rehabil 2008;89:1230-6.

85. Rossato E, Marziali A, Carraro U, et al. Rise2-Italy Project: Muscle FES after peripheral nerve lesion. Basic Appl Myol 2009;19:169-72.

86. Johnston TE, Wainwright SF. Cycling with functional electrical stimulation in an adult with spastic diplegic cerebral palsy. Phys Ther 2011;91: 970-82.

Submission: May, 15, 2019

Revision received: October 31, 2019

Acceptance: October 31, 2019 